\title{
A EXPRESSÃO DO ASPECTO NO PORTUGUÊS
}

\section{THE EXPRESSION OF THE ASPECT IN PORTUGUESE}

\author{
Gisely Gonçalves de Castro ${ }^{1}$ \\ Instituto Federal de Educação, Ciência e Tecnologia do Pará (IFPA) \\ Arabie Bezri Hermont ${ }^{2}$ \\ Pontifícia Universidade Católica de Minas Gerais (PUC Minas)
}

\section{RESUMO}

Este artigo trata da expressão do aspecto no português. Seu objetivo é avaliar os trabalhos sobre a categoria desenvolvidos por Castilho (1968) e Travaglia (2014 [1985]), bem como divulgar materiais produzidos sobre esses trabalhos durante encontros do Grupo de Estudos em Linguagem e Cognição (eLinC) ocorridos no primeiro semestre de 2018. Os procedimentos realizados para alcançar tais objetivos consistiram na revisão teórica dos estudos em questão, na elaboração de diversos quadros para sistematizá-los e na avaliação das propostas de classificação do aspecto neles constantes. Tal avaliação simplificou a profusão de categorias aspectuais presente em Castilho (1968) e Travaglia (2014 [1985]) e ainda forneceu materiais inéditos acerca do assunto.

PALAVRAS-CHAVE: Expressão do Aspecto; Castilho (1968); Travaglia (2014 [1985]).

\begin{abstract}
This paper deals with the expression of the category of aspect in Portuguese. The aim of this work is to evaluate the researches on the aspect developed by Castilho (1968) and Travaglia (2014 [1985]), as well as to disseminate resources produced about these works during meetings of the Group of Study on Language and Cognition (eLinC). In order to achieve this objective, we reviewed the works in question, created several tables and evaluate the default classification of the aspect. This evaluation simplifies the profusion of aspectual categories present in Castilho (1968) and Travaglia (2014 [1985]) studies and also provided unpublished materials on the subject.
\end{abstract}

KEYWORDS: Aspect Expression; Castilho (1968); Travaglia (2014 [1985]).

\section{INTRODUÇÃO}

Dentre os estudos sobre a categoria aspecto no português, dois se destacam pela sua abrangência e profundidade. Refere-se aqui aos estudos de Castilho (1968) e Travaglia (2014 [1985]). Em sua Introdução ao estudo do aspecto verbal na língua portuguesa, Castilho (1968) apresentou o primeiro estudo exclusivo e detalhado sobre a categoria. Mais tarde, na obra $\mathrm{O}$ aspecto verbal no português: a categoria e sua expressão, foi a vez de Travaglia (2014 [1985]) apresentar o estudo mais pormenorizado sobre o aspecto de que se tem notícia.

Este artigo trata da expressão do aspecto no português conforme as propostas de Castilho (1968) e Travaglia (2014 [1985]). O objetivo é avaliar tais propostas, de modo que seja possível simplificar o quadro aspectual do português. Embora consagradas na literatura, as referidas obras apresentam uma profusão de categorias aspectuais, o que pode obscurecer o fenômeno em questão. Assim, uma vez que propõe uma reanálise de uma classificação já consensual, a avaliação que aqui

\footnotetext{
${ }^{1}$ Doutora em Linguística e Língua Portuguesa pela Pontifícia Universidade Católica de Minas Gerais. Foi bolsista do CNPq, processo no 141047/2016-0. E-mail: giselydecastro@gmail.com.

2 Professora do Programa de Pós-Graduação em Letras da Pontifícia Universidade Católica de Minas Gerais e Coordenadora do grupo de pesquisa "Estudos em Linguagem e Cognição (eLinC)”. E-mail: arabie@uol.com.br.
} 
se faz das obras em causa é relevante e necessária. De fato, a partir dessa avaliação, será possível simplificar e atualizar propostas tradicionais, já que, como deverá ficar claro, foi possível reanalisar a maioria dos aspectos propostos pelos autores como interpretações aspectuais decorrentes da relação entre o aspecto gramatical e o aspecto lexical.

Além do mais, este artigo também objetiva divulgar materiais inéditos produzidos para discutir o assunto durante encontros do Grupo de Estudos em Linguagem e Cognição (eLinC) realizados no primeiro semestre de 2018 nas dependências da PUC Minas. Mais especificamente, busca-se apresentar uma série de quadros que foram elaborados para sistematizar as propostas de Castilho (1968) e Travaglia (2014 [1985]). Todos os quadros foram elaborados pelas autoras a partir de um minucioso estudo das obras que embasam este artigo. Com isso, espera-se fornecer, aos interessados nos estudos sobre a categoria aspecto, instrumentos didáticos para consulta.

O fato de este artigo fornecer uma sistematização dos trabalhos de Castilho (1968) e Travaglia (2014 [1985]) não significa que consistirá em um simples resumo dos estudos em questão. Pelo contrário, após a sistematização, será realizada uma avaliação, ainda que incipiente, das propostas em causa com o intuito de demonstrar que o quadro aspectual do português pode ser consideravelmente simplificado se os diversos aspectos aí apresentados forem interpretados como produtos da interação entre o aspecto gramatical, distinções aspectuais marcadas explicitamente por recursos linguísticos, e o aspecto lexical, propriedades aspectuais ligadas à semântica dos predicadores verbais e seus argumentos.

Resta ainda dizer que, evidentemente, este artigo não substitui a leitura dos textos nos quais está embasado. Ao contrário, assume-se aqui que os textos de Castilho (1968) e de Travaglia (2014 [1985]) são de leitura prioritária e indispensável para qualquer um que esteja interessado nas questões pertinentes à categoria aspecto.

Para o cumprimento dos propósitos a que se destina, este artigo encontra-se organizado em cinco seções, sendo a primeira respeitante a esta introdução, a segunda relativa à proposta de Castilho (1967) e aos quadros que a sistematizam, a terceira concernente à proposta de Travaglia (2014 [1985]) e aos quadros que a sistematizam e a quarta relacionada à avaliação de ambas as propostas. Na última seção, realizam-se também algumas considerações finais.

\section{Castilho (1968): Uma introdução ao estudo do aspecto verbal na língua portuguesa}

O trabalho de Castilho (1967) foi o primeiro estudo exclusivo realizado no Brasil sobre a categoria aspecto. Embora reconheça que as noções aspectuais podem ser encontradas em diferentes níveis e categorias ${ }^{3}$, o autor focaliza o verbo a fim de alcançar seu objetivo de estudar o quadro dos aspectos do português e os recursos de que a língua dispõe para sua expressão.

O verbo, nos termos de Castilho (1967, p. 13), é a palavra que pode exprimir diferentes noções relativas a uma situação por meio da mudança de forma. As diferentes noções expressas pelo verbo são codificadas pelas categorias verbais. Em número de seis (modo, tempo, aspecto, voz, pessoa e número), tais categorias atualizam a situação virtualmente considerada, definindo sua duração ou suas fases (aspecto), localizando-a num determinado momento (tempo), esclarecendo a atitude (modo) ou o papel do seu sujeito (voz), explicitando sua relação com o interlocutor e o assunto (pessoa) e, ainda, delimitando a quantidade dessas entidades (número).

Para os propósitos de Castilho (1967), das seis categorias verbais elencadas, destacam-se as de tempo e aspecto, já que constituem os dois mais importantes sistemas gramaticais para expressar conceitos temporais nas diferentes línguas naturais. Para diferenciar aspecto de tempo, o autor contrapõe as noções de objetividade e subjetividade. Nessa perspectiva, tempo é conceituado como uma categoria que localiza a situação num dado momento, servindo-se de pontos de

\footnotetext{
${ }^{3}$ Consideramos o aspecto uma categoria de natureza léxico-sintática, pois em sua caracterização interagem o sentido que a raiz do verbo contém e elementos sintáticos tais como adjuntos adverbiais, complementos e tipo oracional (CASTILHO, 1967, p. 14).
} 
referência o próprio falante, o momento em que se desenrola outro processo e o momento em que idealmente se situa o falante. Como o desvio do ponto de referência faz oscilar todo o sistema, tempo é, então, considerado uma "categoria subjetiva" (CASTILHO, 1967, p. 16).

Já o aspecto seria uma visão objetiva da relação entre uma determinada situação e a ideia de duração ou desenvolvimento, de modo que seja possível visualizar a representação espacial dessa situação (CASTILHO, 1967, p. 14). Assim sendo,

[s]e ação verbal indica uma duração, temos o aspecto imperfectivo; se uma ação cumprida, contrária à noção de duração, o aspecto perfectivo; se uma ação repetida, o aspecto iterativo; se nada disso, vestindo-se o verbo de um tom virtual, indiferente à atualização por qualquer categoria (e no caso interessa-nos a ausência da categoria aspectual), teremos o aspecto indeterminado (CASTILHO, 1967, p. 14).

Como é possível observar na citação acima, Castilho propõe seu quadro aspectual com base nos valores de duração, completamento, repetição e neutralidade. Como cada um desses valores derivam um determinado aspecto, têm-se, então, quatro aspectos fundamentais na língua portuguesa: imperfectivo, derivado da noção de duração; perfectivo, derivado da noção de completamento; iterativo, derivado da noção de repetição; e indeterminado, derivado da noção de neutralidade. O quadro aspectual de Castilho (1967) é reproduzido a seguir:

Quadro 1 - Quadro aspectual de Castilho (1967) resumido

\begin{tabular}{|l|l|l|}
\hline VALOR & ASPECTO & EXEMPLO \\
\hline Duração & Imperfectivo & Ela está falando. \\
\hline Completamento & Perfectivo & O balão estourou. \\
\hline Repetição & Iterativo & Ele levantava cedo. \\
\hline Neutralidade & Indeterminado & Os ângulos do triângulo somam $180^{\circ}$. \\
\hline
\end{tabular}

Fonte: Elaborado pelas autoras com base em Castilho (1967)

Visto que é possível focalizar diferentes fases de uma situação durativa, Castilho (1967) argumenta que o imperfectivo pode ser subdividido em três tipos: inceptivo ${ }^{4}$, quando se reconhece o início da situação; terminativo, quando se reconhece o fim da situação; e cursivo ${ }^{5}$, quando se abstrai o início e o fim da situação.

Assim como ocorre com o imperfectivo, os diferentes matizes da noção de completamento, no entendimento de Castilho (1967), também permitem subdividir o perfectivo em três tipos: pontual, que assinala o começo e o fim da situação concebidos como sendo simultâneos; o resultativo, que indica o resultado decorrente do acabamento da situação; e o cessativo, que indica uma negação que se reporta ao presente.

Dependendo do tipo da situação, se durativa ou pontual, a noção de repetição poderá dar origem a mais dois aspectos: o iterativo imperfectivo ou iterativo perfectivo. Por fim, em caso de neutralidade, isto é, em caso da negação da imperfectividade e da perfectividade, ocorreria o aspecto indeterminado.

\footnotetext{
${ }^{4}$ Para Castilho (1967, p. 49), o inceptivo comporta duas variantes: inceptivo propriamente dito, que diz respeito ao começo puro e simples da ação, e inceptivo incoativo, que se refere à noção de começo da ação seguido de mudança de estado.

${ }^{5}$ De modo semelhante ao que afirmou em relação ao inceptivo, Castilho (1967, p. 49) alegou que o cursivo também pode ser dividido em cursivo propriamente dito e cursivo progressivo, que difere do primeiro por apresentar o processo em seu desenvolvimento gradual.
} 
Com base nessas subdivisões, Castilho (1967) amplia seu quadro aspectual a fim de capturar os aspectos derivados das diferentes nuances dos valores de duração, completamento e repetição.

Quadro 2 - Quadro aspectual de Castilho (1967) ampliado

\begin{tabular}{|l|l|l|l|}
\hline VALOR & ASPECTO & REPRESENTAÇão & EXEMPLO \\
\hline Duração & $\begin{array}{l}\text { Imperfectivo } \\
\text { Inceptivo } \\
\text { Cursivo } \\
\text { Terminativo }\end{array}$ & $\mid-\ldots$ & $\begin{array}{l}\text { Ela começou a falar. } \\
\text { Ela está falando. } \\
\text { Ela parou de falar. }\end{array}$ \\
\hline Completamento & $\begin{array}{l}\text { Perfectivo } \\
\text { Pontual } \\
\text { Resultativo } \\
\text { Cessativo }\end{array}$ & $-\ldots-\mid$ & $\begin{array}{l}\text { O balão estourou. } \\
\text { Tenho a lição estudada. } \\
\text { Éramos estudantes. }\end{array}$ \\
\hline Repetição & $\begin{array}{l}\text { Iterativo } \\
\text { Iterativo imperf. } \\
\text { Iterativo perf. }\end{array}$ & $|-||-||-|$ & $\begin{array}{l}\text { Eles caminhavam à tarde. } \\
\text { Ele levantava cedo. }\end{array}$ \\
\hline Neutralidade & $\begin{array}{l}\text { Indeterminado } \\
\text { Es ân....... }\end{array}$ & & $\begin{array}{l}\text { Os ângulos do triângulo } \\
\text { somam 180 }\end{array}$ \\
\hline
\end{tabular}

Fonte: Elaborado pelas autoras com base em Castilho (1967)

Quanto à expressão do aspecto, Castilho (1967) reconhece que os diferentes aspectos listados no quadro 2, podem ser expressos pelo semantema do verbo, pela flexão temporal, pelos adjuntos adverbiais/conectores e pelos tipos oracionais. Dada a importância do sentido do verbo para a expressão do aspecto, o autor divide os verbos em duas classes semânticas: a télica e a atélica. Enquanto os verbos pertencentes à classe télica descrevem situações que tendem a um fim (1a), os que pertencem à classe atélica descrevem situações que não tendem a um fim necessário (1b).

(1) Classes semânticas

a. Télica: estourar, reconhecer, perceber, encontrar

b. Atélica: falar, caminhar, escrever, trabalhar

Quanto à flexão temporal, Castilho defende que ela só é decisiva na expressão do aspecto quando contorna a tendência aspectual do semantema, conferindo-lhe um valor diferente, o que também vale para os adjuntos adverbiais/conectores. Por exemplo, em (2a), a flexão verbal não seria decisiva na expressão do aspecto, já que o aspecto imperfectivo veiculado pelo pretérito imperfeito não altera o valor de duração inerente ao verbo caminhar. Já em (2b), visto que alteram o valor pontual do verbo cair, o pretérito imperfeito e o adjunto adverbial são decisivos na expressão do aspecto.

(2) A flexão verbal na expressão do aspecto

a. Ela caminhava no parque.

b. A folha caia lentamente.

Castilho (1967) também ressalta a importância das perífrases verbais no que respeita ao contorno de tendências aspectuais e ainda salienta que o complemento do verbo, os tipos oracionais e o contexto parecem estar relacionados com o aspecto. Um exemplo da ação de perífrases verbais sobre o semantema do verbo é dado em (3), em que a perífrase estar + gerúndio contorna o valor pontual intrínseco ao verbo pular, atribuindo-lhe valor de repetição. 
(3) A perífrase verbal na expressão do aspecto

a. A criança pulou.

b. A criança está pulando.

Com base nessas considerações, conclui-se esta seção com a apresentação do quadro 3 , o qual sistematiza os principais meios pelos quais, conforme a proposta de Castilho (1967), a duração, o completamento e a repetição são expressos no português. Recomenda-se que a leitura do quadro seja feita da seguinte forma: [expressão] marca [aspecto]. Para o aspecto inceptivo, por exemplo, uma possibilidade de leitura é a que se segue: a perífrase começar a + infinitivo marca aspecto inceptivo.

Quadro 3 - A expressão do aspecto no português segundo Castilho (1967)

\begin{tabular}{|c|c|c|c|c|}
\hline Aspecto & $\begin{array}{l}\text { Semantema } \\
\text { do verbo }\end{array}$ & $\begin{array}{l}\text { Flexão } \\
\text { Temporal }\end{array}$ & $\begin{array}{l}\text { Perífrases } \\
\text { verbais }\end{array}$ & $\begin{array}{l}\text { Adjuntos } \\
\text { adverbiais/Conecto } \\
\text { res }\end{array}$ \\
\hline Inceptivo & $\begin{array}{l}\text { começar } \\
\text { principiar }\end{array}$ & - & $\begin{array}{l}\text { começar a + inf. } \\
\text { principiar a }+ \text { inf. } \\
\text { passar a + inf. } \\
\text { pôr-se a + inf. }\end{array}$ & $\begin{array}{l}\text { agora } \\
\text { de repente } \\
\text { tempos depois }\end{array}$ \\
\hline Cursivo & $\begin{array}{l}\text { prosseguir } \\
\text { estreitar } \\
\text { aumentar } \\
\text { andar } \\
\text { falar }\end{array}$ & $\begin{array}{l}\text { pres. } \\
\text { pret. imp. } \\
\text { ger. }\end{array}$ & $\begin{array}{l}\text { ficar a }+ \text { inf. } \\
\text { continuar a }+ \text { inf. } \\
\text { estar + inf. } \\
\text { ficar + ger. } \\
\text { continuar + ger. } \\
\text { estar + ger. } \\
\text { ir + ger. } \\
\text { vir + ger. }\end{array}$ & $\begin{array}{l}\text { através dos anos } \\
\text { devagar } \\
\text { lentamente } \\
\text { aos poucos } \\
\text { pouco a pouco } \\
\text { vagarosamente } \\
\text { gradualmente } \\
\text { à medida que } \\
\text { cada vez mais } \\
\text { progressivamente }\end{array}$ \\
\hline Terminativo & $\begin{array}{l}\text { acabar } \\
\text { terminar } \\
\text { cessar }\end{array}$ & - & $\begin{array}{l}\text { acabar de }+ \text { inf. } \\
\text { deixar de }+ \text { inf. } \\
\text { terminar de }+ \text { inf. }\end{array}$ & 1 \\
\hline Pontual & $\begin{array}{l}\text { partir } \\
\text { descobrir }\end{array}$ & $\begin{array}{l}\text { pret. perf. } \\
\text { pret. mqp } \\
\text { fut. perf. }\end{array}$ & $\begin{array}{l}\text { acabar de + inf. } \\
\text { acabar + ger. }\end{array}$ & $\begin{array}{l}\text { abruptamente } \\
\text { repentinamente } \\
\text { completamente } \\
\end{array}$ \\
\hline Resultativo & - & $\begin{array}{l}\text { pret. } \\
\text { part. }\end{array}$ & estar + part. & já \\
\hline Cessativo & - & $\begin{array}{l}\text { pret. perf. } \\
\text { pret. imp. }\end{array}$ & estar + part. & - \\
\hline $\begin{array}{l}\text { Iterativo } \\
\text { imperfectivo }\end{array}$ & - & $\begin{array}{l}\text { pres. } \\
\text { pret. imp. } \\
\text { part. } \\
\text { ger. }\end{array}$ & $\begin{array}{l}\text { Costumar + inf. } \\
\text { andar a + inf. } \\
\text { andar + ger. } \\
\text { viver + ger. }\end{array}$ & \multirow{2}{*}{$\begin{array}{l}\text { sempre } \\
\text { amiúde } \\
\text { às vezes } \\
\text { todos os dias } \\
\text { constantemente } \\
\text { diariamente }\end{array}$} \\
\hline $\begin{array}{l}\text { Iterativo } \\
\text { perfectivo }\end{array}$ & - & $\begin{array}{l}\text { pres. } \\
\text { pret. imp. } \\
\text { part. } \\
\text { ger. }\end{array}$ & $\begin{array}{l}\text { andar } \\
\text { viver }+ \text { gerúndio de } \\
\text { verbo télico }\end{array}$ & \\
\hline Indeterminado & - & $\begin{array}{l}\text { tempos } \\
\text { virtuais }\end{array}$ & - & - \\
\hline
\end{tabular}

Fonte: Elaborado pelas autoras com base em Castilho (1967) 
Conforme o quadro acima, o sistema aspectual do português, na visão de Castilho (1967), é composto pelos aspectos inceptivo, cursivo terminativo, pontual, resultativo, cessativo, iterativo imperfectivo, iterativo perfectivo e indeterminado. Para a expressão desses aspectos, atuam o semantema dos verbos, a flexão temporal, as perífrases verbais e os adjuntos adverbiais/conectores. Tendo sistematizado a proposta de Castilho (1967), passa-se à proposta de Travaglia (2014 [1985]).

\section{Travaglia (2014 [1985]): O aspecto verbal no português - a categoria e sua expressão}

Com o intuito de suprir uma lacuna na descrição do sistema verbal do português, Travaglia (2014 [1985]) apresenta um amplo estudo sobre a categoria aspecto no português brasileiro. São alguns dos objetivos do autor: conceituar o aspecto, estabelecer as noções aspectuais que se expressam no português, apresentar um quadro aspectual do português, verificar de que modo os tipos de situação afetam a atualização do aspecto e determinar os meios de expressão do aspecto.

Para atingir os três primeiros objetivos, Travaglia (2014 [1985]) se concentra nas noções de duração e de fase. Nesse contexto, o aspecto é conceituado como uma categoria verbal de tempo, não dêitica, através da qual se marca a duração da situação e suas fases. Já as noções aspectuais e o quadro aspectual do português são derivados das noções básicas de duração e fase, conforme mostra o quadro 4, que foi adaptado de Travaglia (2014 [1985], p. 85).

\begin{tabular}{|c|c|c|c|}
\hline \multicolumn{4}{|c|}{ Quadro 4 - Quadro aspectual de Travaglia (2014 [1985]) } \\
\hline Noções básicas & $\begin{array}{l}\text { Noções } \\
\text { aspectuai } \\
\text { s }\end{array}$ & Aspectos & Conceitos \\
\hline \multirow{5}{*}{ Duração } & $\begin{array}{l}\text { Contínua } \\
\text { limitada }\end{array}$ & Durativo & $\begin{array}{l}\text { Apresenta a situação sem interrupção em } \\
\text { seu tempo de existência e com seus limites } \\
\text { demarcados }\end{array}$ \\
\hline & $\begin{array}{l}\text { Contínua } \\
\text { ilimitada }\end{array}$ & $\begin{array}{l}\text { Indetermina } \\
\text { do }\end{array}$ & $\begin{array}{l}\text { Apresenta a situação sem interrupção em } \\
\text { seu tempo de existência e com seus limites } \\
\text { não demarcados }\end{array}$ \\
\hline & $\begin{array}{l}\text { Descontín } \\
\text { ua limitada }\end{array}$ & Iterativo & $\begin{array}{l}\text { Apresenta a situação com interrupção em } \\
\text { seu tempo de existência e com seus limites } \\
\text { demarcados }\end{array}$ \\
\hline & $\begin{array}{l}\text { Descontín } \\
\text { ua } \\
\text { ilimitada }\end{array}$ & Habitual & $\begin{array}{l}\text { Apresenta a situação com interrupção em } \\
\text { seu tempo de existência e com seus limites } \\
\text { não demarcados }\end{array}$ \\
\hline & $\begin{array}{l}\text { Não } \\
\text { duração }\end{array}$ & Pontual & $\begin{array}{l}\text { Apresenta a situação como não tendo } \\
\text { duração. }\end{array}$ \\
\hline \multirow{3}{*}{$\begin{array}{l}\text { Fases de } \\
\text { realização }\end{array}$} & $\begin{array}{l}\text { Por } \\
\text { começar }\end{array}$ & $\begin{array}{l}\text { Não } \\
\text { começado }\end{array}$ & $\begin{array}{l}\text { Apresenta a situação como algo ainda por } \\
\text { ocorrer }\end{array}$ \\
\hline & Começado & Começado & Apresenta a situação já em realização \\
\hline & Acabado & Acabado & $\begin{array}{l}\text { Apresenta a situação como terminada, } \\
\text { concluída }\end{array}$ \\
\hline \multirow{3}{*}{$\begin{array}{c}\text { Fases de } \\
\text { desenvolvimento }\end{array}$} & Início & Inceptivo & $\begin{array}{l}\text { Apresenta a situação em seu ponto de início } \\
\text { ou seus primeiros momentos }\end{array}$ \\
\hline & Meio & Cursivo & $\begin{array}{l}\text { Apresenta a situação em seu pleno } \\
\text { desenvolvimento }\end{array}$ \\
\hline & Fim & Terminativo & $\begin{array}{l}\text { Apresenta a situação em seu ponto de } \\
\text { término ou em seus últimos momentos }\end{array}$ \\
\hline
\end{tabular}




\begin{tabular}{|c|l|l|l|}
\hline $\begin{array}{c}\text { Fases de } \\
\text { completamento }\end{array}$ & Completo & Perfectivo & $\begin{array}{l}\text { Apresenta a situação em uma de suas fases } \\
\text { de desenvolvimento }\end{array}$ \\
\cline { 2 - 4 } & $\begin{array}{l}\text { Incomplet } \\
\text { o }\end{array}$ & $\begin{array}{l}\text { Imperfectiv } \\
\text { o }\end{array}$ & $\begin{array}{l}\text { Apresenta a situação com seu início, meio e } \\
\text { fim englobados num todo }\end{array}$ \\
\hline
\end{tabular}

Fonte: Elaborado pelas autoras com base em Travaglia (2014 [1985])

Quanto ao quarto objetivo, qual seja, verificar de que modo os tipos de situação afetam a atualização do aspecto, além da distinção télica/atélica tratada anteriormente por Castilho (1967), Travaglia (2014 [1985]) considera ainda as oposições entre situação dinâmica e situação estática e situação narrada e situação referencial. De acordo com o autor, quando as fases de uma situação são diferentes ela é dinâmica (4a). Por outro lado, quando todas as fases são idênticas, a situação é estática (4b).

(4) Tipos de situação: dinâmica/estática

a. Os alunos resolveram o problema.

b. Os alunos sabem matemática.

Para explicar os casos em que uma mesma forma se associa a aspectos incompatíveis, Travaglia (2014 [1985]) estabelece a distinção entre situação narrada e situação referencial. Conforme o autor, a incompatibilidade entre aspectos ocorrerá sempre que um determinado aspecto estiver associado a outro do mesmo grupo. Por exemplo, no grupo fases de completamento, o aspecto perfectivo é incompatível com o aspecto imperfectivo, já que uma situação não pode ser apresentada como perfectiva e imperfectiva ao mesmo tempo. Dessa forma, sempre que houver incompatibilidade entre aspectos, a proposta do estudioso é que eles estarão se referindo a situações distintas, isto é, um deles estará se referindo à situação referencial e o outro à situação narrada.

Conforme Travaglia (2014 [1985], p. 70-71), a situação referencial e a situação narrada estão relacionadas por um dos três motivos: (i) a situação referencial é um estado resultante da realização anterior da situação narrada (5a) ou um estado anterior à realização da situação narrada (5b); (ii) a situação referencial é uma situação cuja realização implica o início (5c) ou término (5d) de outra situação, que é a situação narrada; e (ii) a situação referencial é uma situação cuja realização implica o prosseguimento da realização da situação narrada, cujo término era esperado (5e).

(5) Relação entre situação narrada e situação referencial

a. O vaso está quebrado.

b. A cozinha está por limpar.

c. O conferencista começou a falar há meia hora.

d. Rita terminou de limpar a casa às 11 horas.

e. Carla continuou caminhando pelo bosque, embora todos já tivessem voltado para casa. (TRAVAGLIA, 2014 [1985], p. 66, 70)

Essa distinção está diretamente relacionada ao último objetivo de Travaglia (2014 [1985]) listado no início desta seção, a saber, determinar os meios de expressão do aspecto. Os quadros a seguir sistematizam a expressão do aspecto no português conforme a proposta de Travaglia (2014 [1985]). Enquanto o quadro 5 apresenta a expressão do aspecto pela flexão verbal, os quadros $6 \mathrm{e}$ 7 apresentam a expressão do aspecto pelas perífrases verbais.

Quadro 5 - Expressão dos aspectos pela flexão verbal

\begin{tabular}{|c|l|l|l|l|l|}
\hline Expressão & $\begin{array}{l}\text { Pres. do } \\
\text { ind. }\end{array}$ & $\begin{array}{l}\text { Pret. } \\
\text { imperf. do } \\
\text { ind. }\end{array}$ & $\begin{array}{l}\text { Pret. perf. do } \\
\text { ind. }\end{array}$ & $\begin{array}{l}\text { Pret. m-q-perf. } \\
\text { do ind. }\end{array}$ & $\begin{array}{l}\text { Tempos } \\
\text { do Subj.* }\end{array}$ \\
\hline
\end{tabular}




\begin{tabular}{|c|c|c|c|c|c|}
\hline Durativo & $\begin{array}{l}\text { semantema } \\
\text { do verbo }\end{array}$ & $\checkmark$ & $\begin{array}{l}\text { verbo estático } \\
\text { adj. adv. } \\
\text { oração adv. } \\
\text { repetição do } \\
\text { verbo }\end{array}$ & $\begin{array}{l}\text { verbo estático } \\
\text { adj. adv. } \\
\text { oração adv. } \\
\text { repetição do } \\
\text { verbo }\end{array}$ & $\begin{array}{l}\text { semantem } \\
\text { a do verbo }\end{array}$ \\
\hline $\begin{array}{l}\text { Indeterminad } \\
\mathrm{o}\end{array}$ & $\sqrt{ }$ & $\sqrt{ }$ & - & - & $\begin{array}{l}\text { pres. e } \\
\text { pret. } \\
\text { imperf.. }\end{array}$ \\
\hline Iterativo & - & - & adj. adv. & adj. adv. & - \\
\hline Habitual & $\sqrt{ }$ & $\sqrt{ }$ & adj. adv. & adj. adv. & $\begin{array}{l}\text { pres. e } \\
\text { pret. } \\
\text { imperf. }\end{array}$ \\
\hline Pontual & $\begin{array}{l}\text { descrição } \\
\text { simultânea } \\
\text { e verbo } \\
\text { pontual }\end{array}$ & - & verbo pontual & verbo pontual & - \\
\hline Começado & $\checkmark$ & - & - & - & $\checkmark$ \\
\hline Acabado & adj. adv. & $\begin{array}{l}\text { verbo } \\
\text { estático } \\
\text { atélico } \\
\text { com } \\
\text { ênfase } \\
\text { entonacio } \\
\text { nal }\end{array}$ & $\begin{array}{l}\text { verbos } \\
\text { estáticos télico }\end{array}$ & $\checkmark$ & - \\
\hline Cursivo & $\checkmark$ & $\checkmark$ & - & - & $\checkmark$ \\
\hline Perfectivo & $\begin{array}{l}\text { descrição } \\
\text { simultânea } \\
\text { e verbo } \\
\text { pontual }\end{array}$ & - & $\checkmark$ & $\sqrt{ }$ & - \\
\hline Imperfectivo & $\sqrt{ }$ & $\checkmark$ & - & - & $\checkmark$ \\
\hline
\end{tabular}

Para fins de interpretação do quadro 5 , o sinal de verificação $(\boldsymbol{V})$ será lido como marca, o traço (-) será lido como não marca e o conteúdo das células que não compõem a linha do cabeçalho nem a primeira coluna será o contexto em que a expressão do aspecto ocorre. Por exemplo, para o aspecto perfectivo, têm-se as seguintes possibilidades de leitura: o presente do indicativo marca aspecto perfectivo em descrições simultâneas e com verbos pontuais, o pretérito imperfeito do indicativo não marca aspecto perfectivo, o pretérito perfeito do indicativo marca aspecto perfectivo e assim por diante. O próximo quadro segue a mesma estratégia de leitura. Uma vez que, segundo a proposta de Travaglia (2014 [1985]), as perífrases podem marcar aspectos incompatíveis, a situação referencial (SR) e a situação narrada (SN) foram consideradas no quadro em questão.

Quadro 6 - expressão dos aspectos pelas perífrases de ter/haver, estar, ir e vir

\begin{tabular}{|c|c|c|c|c|c|c|c|}
\hline Exp. & $\begin{array}{l}\text { Ter/ha } \\
\text { ver }+ \\
\text { particíp } \\
\text { io } \\
\text { (invariá }\end{array}$ & $\begin{array}{l}\text { Ter/have } \\
\mathrm{r}+ \\
\text { particípio } \\
\text { (variável) }\end{array}$ & $\begin{array}{l}\text { Estar }+ \\
\text { por/para } \\
\text { /em }+ \\
\text { infinitivo }\end{array}$ & $\begin{array}{l}\text { Estar + } \\
\text { gerúndio }\end{array}$ & $\begin{array}{l}\text { Estar + } \\
\text { particípio }\end{array}$ & $\begin{array}{l}\text { Ir }+ \\
\text { gerúndio }\end{array}$ & $\begin{array}{l}\text { Vir + } \\
\text { gerúndio }\end{array}$ \\
\hline
\end{tabular}




\begin{tabular}{|c|c|c|c|c|c|c|c|}
\hline 离 & $\begin{array}{l}\text { No pres. } \\
\text { ind. com } \\
\text { verbos } \\
\text { que } \\
\text { indicam } \\
\text { situações } \\
\text { contínua } \\
\text { s }\end{array}$ & Para a SR & Para a SR & Para a SR & Para a SR & $\begin{array}{l}\text { Com } \\
\text { todas as } \\
\text { flexões } \\
\text { verbais }\end{array}$ & $\begin{array}{l}\text { Com } \\
\text { todas as } \\
\text { flexões } \\
\text { verbais }\end{array}$ \\
\hline . & $\begin{array}{l}\text { No pres. } \\
\text { ind. }\end{array}$ & - & - & - & - & - & - \\
\hline 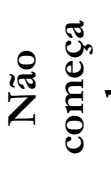 & - & - & Para a SN & - & - & - & - \\
\hline 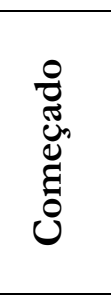 & $\begin{array}{l}\text { No pres. } \\
\text { ind. }\end{array}$ & $\begin{array}{l}\text { Para a SR, } \\
\text { exceto } \\
\text { nos pret. } \\
\text { perf. e m. } \\
\text { q. perf. } \\
\text { ind. }\end{array}$ & $\begin{array}{l}\text { Para a SR, } \\
\text { exceto } \\
\text { nos pret. } \\
\text { perf. e m. } \\
\text { q. perf. } \\
\text { ind. }\end{array}$ & $\begin{array}{l}\text { Para a SR, } \\
\text { exceto } \\
\text { nos pret. } \\
\text { perf. e m. } \\
\text { q. perf. } \\
\text { ind. }\end{array}$ & $\begin{array}{l}\text { Para a SR, } \\
\text { exceto } \\
\text { nos pret. } \\
\text { perf. e m. } \\
\text { q. perf. } \\
\text { ind. }\end{array}$ & - & $\begin{array}{l}\text { Exceto } \\
\text { nos pret. } \\
\text { pert. e m. } \\
\text { q. perf. } \\
\text { ind. }\end{array}$ \\
\hline$\frac{0}{\frac{\pi}{\pi}}$ & $\begin{array}{l}\text { Exceto } \\
\text { no pres. } \\
\text { ind. }\end{array}$ & $\begin{array}{l}\text { Para a SN, } \\
\text { e para SR } \\
\text { nos pret. } \\
\text { per,f. e m. } \\
\text { q. perf. } \\
\text { ind. }\end{array}$ & $\begin{array}{l}\text { Para a SR } \\
\text { nos pret. } \\
\text { perf. e m. } \\
\text { q. perf. } \\
\text { ind. }\end{array}$ & $\begin{array}{l}\text { Para a SR } \\
\text { nos pret. } \\
\text { perf. e m. } \\
\text { q. perf. } \\
\text { ind. }\end{array}$ & $\begin{array}{l}\text { Para a SN, } \\
\text { e ara a SR } \\
\text { nos pret. } \\
\text { perf. e m. } \\
\text { q. perf. } \\
\text { ind. }\end{array}$ & - & - \\
\hline : & - & $\begin{array}{l}\text { Para a SR, } \\
\text { exceto } \\
\text { nos pret. } \\
\text { perf. e m. } \\
\text { q. perf. } \\
\text { ind. }\end{array}$ & $\begin{array}{l}\text { Para a SR, } \\
\text { exceto } \\
\text { nos pret. } \\
\text { perf. e m. } \\
\text { q. perf. } \\
\text { ind. }\end{array}$ & $\begin{array}{l}\text { Para a SR, } \\
\text { exceto } \\
\text { nos pret. } \\
\text { perf. e m. } \\
\text { q. perf. } \\
\text { ind. }\end{array}$ & $\begin{array}{l}\text { Para a SR, } \\
\text { exceto } \\
\text { nos pret. } \\
\text { perf. e m. } \\
\text { q. perf. } \\
\text { ind. }\end{array}$ & - & $\begin{array}{l}\text { Exceto } \\
\text { nos pret. } \\
\text { pert. e m. } \\
\text { q. perf. } \\
\text { ind. }\end{array}$ \\
\hline 总 & $\begin{array}{l}\text { Exceto } \\
\text { no pres. } \\
\text { ind. }\end{array}$ & $\begin{array}{l}\text { Para a SR } \\
\text { nos pret. } \\
\text { perf. e m. } \\
\text { q. perf. } \\
\text { ind }\end{array}$ & $\begin{array}{l}\text { Para a SR, } \\
\text { nos pret. } \\
\text { perf. e m. } \\
\text { q. perf. } \\
\text { ind. }\end{array}$ & $\begin{array}{l}\text { Para a SR, } \\
\text { nos pret. } \\
\text { perf. e m. } \\
\text { q. perf. } \\
\text { ind. }\end{array}$ & $\begin{array}{l}\text { Para a SR, } \\
\text { nos pret. } \\
\text { perf. e m. } \\
\text { q. perf. } \\
\text { ind. }\end{array}$ & - & $\begin{array}{l}\text { Nos pret. } \\
\text { perf. ind. } \\
\text { e m. q. } \\
\text { perf. ind. }\end{array}$ \\
\hline 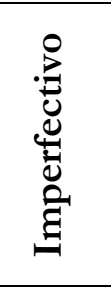 & $\begin{array}{l}\text { No pres. } \\
\text { ind. }\end{array}$ & $\begin{array}{l}\text { Para a SR, } \\
\text { exceto } \\
\text { nos pret. } \\
\text { perf. e m. } \\
\text { q. perf. } \\
\text { ind. }\end{array}$ & $\begin{array}{l}\text { Para a SR, } \\
\text { exceto } \\
\text { nos pret. } \\
\text { perf. e m. } \\
\text { q. perf. } \\
\text { ind. }\end{array}$ & $\begin{array}{l}\text { Para a SR, } \\
\text { exceto } \\
\text { nos pret. } \\
\text { perf. e m. } \\
\text { q. perf. } \\
\text { ind. }\end{array}$ & $\begin{array}{l}\text { Para a SR, } \\
\text { exceto } \\
\text { nos pret. } \\
\text { perf. e m. } \\
\text { q. perf. } \\
\text { ind. }\end{array}$ & - & $\begin{array}{l}\text { Exceto } \\
\text { nos pret. } \\
\text { pert. e m. } \\
\text { q. perf. } \\
\text { ind. }\end{array}$ \\
\hline
\end{tabular}

Fonte: Elaborado pelas autoras com base em Travaglia (2014 [1985])

O próximo quadro, dedicado às perífrases iterativas e habituais, mantém o procedimento de leitura dos anteriores. Com ele, conclui-se esta seção e espera-se que dois objetivos deste artigo, 
quais sejam, sistematizar as propostas de Castilho (1967) e Travaglia (2014 [1985]) e divulgar materiais produzidos durante encontros do grupo de pesquisa eLinC, tenham sido alcançados.

Quadro 7 - Expressão dos aspectos pelas perífrases iterativas e habituais

\begin{tabular}{|l|l|l|l|l|}
\hline \multicolumn{1}{|c|}{$\begin{array}{l}\text { Expressão } \\
\text { Aspecto }\end{array}$} & $\begin{array}{l}\text { Andar }+ \\
\text { gerúndio }\end{array}$ & $\begin{array}{l}\text { Viver }+ \\
\text { gerúndio } \\
\text { Viver }+ \\
\text { particípio }\end{array}$ & $\begin{array}{l}\text { Costumar }+ \\
\text { infinitivo }\end{array}$ & $\begin{array}{l}\text { Usar }+ \\
\text { Infinitivo }\end{array}$ \\
\hline Iterativo & $\begin{array}{l}\text { com todas as } \\
\text { flexões verbais }\end{array}$ & - & - & - \\
\hline Habitual & - & $\begin{array}{l}\text { com todas as } \\
\text { flexões verbais }\end{array}$ & $\begin{array}{l}\text { com todas as } \\
\text { flexões verbais }\end{array}$ & $\begin{array}{l}\text { com todas as } \\
\text { flexões verbais }\end{array}$ \\
\hline Começado & $\begin{array}{l}\text { exceto nos pret. } \\
\text { pert. e m. q. } \\
\text { perf. ind. }\end{array}$ & $\begin{array}{l}\text { com todas as } \\
\text { flexões verbais }\end{array}$ & - & - \\
\hline Perfectivo & $\begin{array}{l}\text { nos pret. perf. } \\
\text { ind. e m. q. } \\
\text { perf. ind. }\end{array}$ & - & - & - \\
\hline imperfectivo & $\begin{array}{l}\text { exceto nos pret. } \\
\text { pert. e m. q. } \\
\text { perf. ind. }\end{array}$ & $\begin{array}{l}\text { com todas as } \\
\text { flexões verbais }\end{array}$ & - & - \\
\hline
\end{tabular}

Fonte: Elaborado pelas autoras com base em Travaglia (2014 [1985])

Para que se possa alcançar, de modo integral, os propósitos deste trabalho, apresenta-se, na próxima seção, uma avaliação das propostas trazidas nas seções anteriores. Com isso, busca-se demonstrar que o quadro aspectual do português pode ser consideravelmente simplificado se os diversos aspectos propostos por Castilho (1967) e Travaglia (2014 [1985]) forem interpretados como resultados da interação entre o aspecto gramatical e o aspecto lexical.

\section{Avaliação das propostas de Castilho (1967) e Travaglia (2014 [1985])}

Uma análise dos estudos de Castilho (1967) e Travaglia (2014 [1985]) sobre o aspecto mostra que os autores lidam com diversas categorias. De fato, enquanto Castilho (1967) trabalha com nove categorias, incluindo aí o aspecto indeterminado, Travaglia (2014 [1985]) opera com três a mais, totalizando treze. Essa profusão de categorias pode fazer com que o fenômeno pareça mais complexo do que realmente é. Dessa forma, busca-se, nesta seção, demonstrar que o quadro aspectual do português pode ser consideravelmente simplificado se os diversos aspectos propostos pelos autores forem tratados com base na interação entre o aspecto gramatical e o aspecto lexical.

Embora presente nas seções anteriores sob a denominação de classe semântica (seção 2) e tipo de situação (seção 3), o aspecto lexical não foi abordado de maneira explícita pelos autores. A referência ao aspecto gramatical foi feita, nos dois estudos em questão, quando do tratamento da expressão de aspecto pela flexão e pela perífrase verbal.

Por aspecto gramatical entendem-se as distinções marcadas explicitamente por recursos linguísticos, como é o caso da flexão e da perífrase. Quanto ao aspecto lexical, cuja classificação mais conhecida é a que foi instituída por Vendler (1957), assume-se que se trata das propriedades aspectuais ligadas aos predicadores verbais e seus argumentos. As classes de Vendler (1957) são: estados (instantes de tempo indefinidos), atividades (períodos de tempo indefinidos), accomplishments (períodos de tempo definidos) e achievements (instantes de tempo definidos).

$\mathrm{Na}$ literatura, diversas propostas consideram a interação entre o aspecto gramatical e o aspecto lexical, como a de Comrie (1976), que discute o princípio da naturalidade de combinação, 
a de Smith (1997), que estabelece a distinção entre aspecto da situação e aspecto do ponto de vista, e a de Verkuyl (1993), que opõe aspectualidade interna e aspectualidade externa.

Nessa perspectiva, propõe-se que muitas das categorias apresentadas nas seções anteriores sejam reanalisadas como interpretações aspectuais derivadas da interação entre o aspecto lexical e o aspecto gramatical. Por exemplo, para a categoria analisada tanto em Castilho (1967) quanto em Travaglia (2014 [1985]) como aspecto iterativo, a sugestão que aqui se faz é a reanálise do valor iterativo, de modo que ele seja uma interpretação aspectual decorrente da interação entre o aspecto lexical pontual e o aspecto gramatical imperfectivo. Essa e outras possibilidades de interação são apresentadas no quadro a seguir, em que AL significa aspecto lexical e AG significa aspecto gramatical.

Quadro 8 - Interação entre o aspecto lexical e o aspecto gramatical

\begin{tabular}{|l|l|l|l|l|}
\hline AG & Estado & Atividade & Accomplishment & Achievement \\
\hline Imperfectivo & $\begin{array}{l}\text { indeterminado } \\
\text { durativo }\end{array}$ & $\begin{array}{l}\text { cursivo } \\
\text { habitual } \\
\text { começado }\end{array}$ & $\begin{array}{l}\text { cursivo } \\
\text { habitual } \\
\text { começado }\end{array}$ & $\begin{array}{l}\text { não começado } \\
\text { iterativo }\end{array}$ \\
\hline Perfectivo & $\begin{array}{l}\text { durativo } \\
\text { inceptivo }\end{array}$ & completo & acabado & $\begin{array}{l}\text { acabado } \\
\text { pontual }\end{array}$ \\
\hline
\end{tabular}

Fonte: Elaborado pelas autoras.

De acordo com o quadro 8, noções como as de indeterminação, duração, pontualidade e diversas outras devem ser expressas não em termos de categorias aspectuais, mas em função da interação entre o aspecto lexical e o aspecto gramatical. Portanto, chega-se à conclusão de que a análise do aspecto, conforme proposta por Castilho (1967) e Travaglia (2014 [1985]), pode ser consideravelmente simplificada quando se considera a relação entre os dois sistemas de categorias inerentes ao conceito de aspecto: o que pertence à gramática (perfectivo e imperfectivo) e o que diz respeito à sua expressão lexical dos tipos de situação (estado, atividade, accomplishment e achievement). Seguem, na próxima seção, as considerações finais deste artigo.

\section{CONSIDERAÇÕES FINAIS}

Este artigo abordou a expressão do aspecto no português conforme os trabalhos desenvolvidos por Castilho (1968) e Travaglia (2014 [1985]). O objetivo foi sistematizar e avaliar os estudos em questão, bem como divulgar materiais produzidos durante encontros do eLinC. A sistematização foi realizada nas seções 2 e 3, sendo esta dedicada ao estudo de Travaglia (2014 [1985]), e aquela voltada para o texto de Castilho (1968). A avaliação, por seu turno, foi empreendida na seção 4. O quadro 8 , que aí se propôs mostrou-se pertinente à discussão deste texto e permitiu chegar à conclusão de que é possível reduzir o número de categorias aspectuais do português a partir da interação entre o aspecto gramatical e o aspecto lexical.

Dessa forma, espera-se que este artigo possa contribuir para o prosseguimento dos estudos acerca do aspecto no português. Com a divulgação dos quadros produzidos durante encontros do eLinC, espera-se ainda fornecer, aos interessados nos estudos acerca da categoria em causa, um instrumento didático para consultas. Por fim, é preciso ressaltar ainda o caráter incipiente do quadro 8 (seção 4) e, consequentemente, a necessidade de um trabalho mais pormenorizado capaz de capturar distinções mais refinadas como a subcategoria de aspecto imperfectivo progressivo.

\section{REFERÊNCIAS}

CASTILHO, A.T. Nova Gramática do Português Brasileiro. São Paulo: Contexto, 2016. 
COMRIE, B. Aspect. Cambridge: Cambridge University Press, 1976.

SMITH, C. S. The Parameter of Aspect. 2a. ed. Dordrecht: Springer Science+Business , v. 43, 1997.

TRAVAGLIA, L. C. O aspecto verbal no português: a categoria e sua expressão. 2a. ed. Uberlândia: EDUFU, 2014 [1985].

VERKUYL, H. J. A theory of aspectuality. Cambridge: Cambridge University Press, 1993.

VENDLER, Z. Verbs and Times. The Philosophical Review, v. 66, n. 2, p. 143-160, 1957.

Submetido em 21/11/2019

Aceito em $02 / 01 / 2020$

Publicado em 07/02/2020 